\title{
The Status of Career Awareness among Selected Kenyan Public Secondary School Students
}

\author{
Fr Racho Ibrahim \\ Catholic University of Eastern Africa, Kenya \\ Dr Pascal Wambiya \\ Co-ordinator of Academic Programmes, Catholic University of Eastern Africa, \\ Kenya P.O. BOX 62157, 00200, Nairobi, Kenya. \\ Email:pwambiya@cuea.edu \\ Dr Peter J.O. Aloka \\ Jaramogi Oginga Odinga University of Science and Technology, Kenya \\ Dr Pamela Raburu \\ Jaramogi Oginga Odinga University of Science and Technology, Kenya
}

\section{Doi:10.5901/jesr.2014.v4n6p301}

\begin{abstract}
The study investigated the status of career awareness among public secondary school students in Marsabit Central district, Kenya. The study adopted descriptive survey design. The target population of students was 2,259, nine guidance and counselling teachers. 250 students in the district were selected using stratified sampling technique. Six guidance and counselling teachers representing $67 \%$ of the 9 guidance and counselling teachers in the district were also randomly selected for the study. The researcher used questionnaires and interviews to elicit information from students and interview schedules to collect data from counselling teachers and principals. The findings indicated that, students' career awareness had significant relationship with students', $(\chi 2=56.250, d f=49, p=0.001<0.05)$ career decisions. That is, the students who were aware of careers were able to make career decisions, while those who were not aware of careers had difficulty making career decisions. This implies that effective career guidance and counselling could help students to be aware of careers and this enabled them to be able to make right career decisions. The study recommended that school counsellors should provide a systematic approach to helping all students with the decision making process, to understand; themselves and to develop appropriate goals through the interpretation of standardized test results and course performance.
\end{abstract}

Keywords: Status, career awareness, Kenyan, public, secondary school, students

\section{Introduction}

Guidance and counselling is an integral and requisite part of any education system and a lot of emphasis should be laid on its implementation to ensure that its roles and objectives are realized. Guidance and counseling provides information in three critical areas: academic, personal/social, and career (Watts, 2010). In secondary school system, this information can help students resolve emotional, social or behavioral problems and help them develop a clearer focus or sense of direction. Effective counseling programs are important to the school climate and a crucial element in improving student achievement and career development (Cheek \& Bradley, 2009). Career guidance and counselling services which are components of the guidance and counselling programme are vital activities because one of the long-term goals of education is career placement (McLeod, 2007). If education is to realize this goal, then learners should have appropriate career information and undertake career exploration before making career choices. This aspect of learning can only be effectively handled under the context of guidance and counseling; to create career awareness and career planning that will then influence learners' career decisions (Strong, 2009). Career guidance activities in secondary schools should focus on career education, career awareness, career planning, and placement. The role of career guidance and 
counseling in schools is to foster the career development of learners and enable them to choose the right courses in post-secondary education (Gazda, 2008). Therefore, lack of it undermines the economic productivity of a country due to lack of proper career preparation, training, placement, and satisfaction (George \& Cristiani, 2012). Students in secondary schools may not have the necessary information concerning careers and being in their adolescent stage, should be helped to choose suitable careers, make the necessary preparations for it, enter into it in college and develop in it (Cheek \& Bradley, 2009).

In Kenya, counselling in the school has been promoted to help improve participation and achievement of students in different areas. In 1971, the Ministry of Education introduced guidance and counseling in schools in recognition that academic work alone would not help the students to make informed choices in life including career decision making (Makinde, 2006). Its vitality was amplified by a range of students' behavioral problems experienced in many schools. The Kenyan Ministry of Education under which this programme was founded identified various components used to create a benchmark for effective school guidance and counseling services against which it could be assessed in Kenyan schools. The components included policy and mission statements; services planning; needs assessment services; responsive services; peer counseling and services evaluation of developed countries like America, the United Kingdom, Canada, Hong Kong, Scotland, China and Ireland and of developing countries like South Africa, Malawi, Zambia, Uganda and Botswana (Duda, 2006). This and other programmes such as the United Nations Educational Scientific and Cultural Organization programme on guidance counselling and youth development for Africa (UNESCO Modules 1-8, 2006) that promotes guidance and counseling as an integral part of the education of students and essential life skills (Dakar framework VI, 2007) are meant among other things to enhance the participation and achievement in education.

The Ministry of Education through the Basic Education Act 112 introduced guidance and counselling as a mandatory program in all public schools in Kenya with the ultimate goal to assist students develop their academic, social and personal competencies in order to make realistic choices and relevant decisions in life (MOEST, 2007). However, this basic guidance and counselling programme has not been realized up to date. As such, there is a growing concern by counselling practitioners, teachers and parents about the realization of these objectives. Since basic counselling has not been realized, career counselling which is a component of guidance and counselling is an area that is poorly explored in Kenya (Wango, 2006). This lack of quality career guidance in most Kenyan public secondary schools is partly attributed to shortage of human and time resources that the process demands and has led to choice of unsuitable careers resulting in widespread poor performance at the workplace (Rob \& Achola, 2008). In addition, they found out that counsellors provided career guidance only to students who showed interest and was dependent on voluntary efforts by some teachers who felt motivated to do it. Moreover, teachers had an overloaded curriculum and little or no time for counselling; teachers lacked basic tools like books and rooms and teachers identified for the purpose had not been trained and so had no professional competence in the subject. A consideration of the above shows that there is a greater challenge ahead in basic guidance and counselling programs and thus, career counselling in public secondary schools. This problem needed a scientific inquiry in order to enhance basic and career guidance and counselling in secondary schools. However, despite the importance that seems to have been attached to guidance and counseling services in Kenyan schools, especially public secondary schools, the programme has not been evaluated fully as to the extent to which it can help secondary school students to make realistic career decisions in line with one of the Ministry of Education policies (Wango, 2007).

\section{Theoretical Framework and Literature Review}

\subsection{The Super's Self-concept theory of career development}

The theory of self-concept of career development was used to underpin the study. Among the many theories of career choice and development, the theory by Super (2007) has received much attention in many parts of the world. Super (2007) suggested that career choice and development is essentially a process of developing and implementing a person's self-concept. According to Super (2007), self-concept is a product of complex interactions among a number of factors, including physical and mental growth, personal experiences, and environmental characteristics and stimulation. In this light, Marsabit Central district being in remote and marginalized part of Kenya may have influence in some students' self-concept and affect the choice of career due to their personal experiences or environmental characteristics. Whereas Super presumed that there is an organic mechanism acting behind the process of development and maturation, recent articulations (Savickas, 2012) of Super's theory have called for a stronger emphasis on the effects of social context and the reciprocal influence between the person and the environment. Building on super's notion that self- 
concept theory was essentially a personal construct theory; Savickas (2012) took a constructivist perspective and postulated that the process of career construction is essentially that of developing and implementing vocational selfconcepts in work roles. Therefore, relatively stable self-concept should emerge in late adolescence to serve as a guide to career choice and adjustment. However, this theory has also received some criticism because self-concept is not a static entity and it would continue to evolve as the person encounters new experience and progresses through the developmental stages. In addition, life and work satisfaction is a continual process of implementing the evolving selfconcept through work and other life roles (Savickas, 2012).

Super (2007) proposed a life stage developmental framework with the following stages: growth, exploration, establishment, maintenance (or management), and disengagement. In each stage, one has to successfully manage the vocational developmental tasks that are socially expected of persons in the given chronological age range. For example, in the stage of exploration (ages around 15 to 24), an adolescent has to cope with the vocational developmental tasks of crystallization (a cognitive process involving an understanding of one's interests, skills, and values, and to pursue career goals consistent with that understanding), specification (making tentative and specific career choices), and implementation (taking steps to actualize career choices through engaging in training and job positions). Accordingly, the concept of "career maturity" was used to denote the degree that a person was able to fulfil the vocational developmental tasks required in each developmental stage.

\subsection{Literature Review}

Studies have been reported on the Status of Guidance and Counselling Services Awareness among Students. Trusty (2006) conducted a study in 4 high schools in England in order to establish students' career exploration and readiness. He reported that many counsellors were already engaging with students in conversations about course selection, goals and postsecondary education, as well as career and financial planning. This was evidenced through career tests which were administered to fourth grade students in most schools that were selected. Clinedinst and Hawkins (2009) conducted a cohort national survey in Massachusetts to find out the level of career awareness among high school students. The study findings were that, counsellors spent on average 7 percent of their time on occupational counselling and job placement, compared to the 26 percent of time spent on post-secondary admission counselling. Because only 69 percent of high school graduates enrolled in post-secondary institutions, many of the 31 percent who remained were left to enter the job market soon after high school. Although some research has found that counsellors administering careerpreparation programs at the middle school level had little to no measurable impact on the career preparedness of students, there is substantial research supporting the value of career planning and guidance at both the middle and secondary levels. Accordingly, research on career decision-making among high school students by Chapman (2010) has shown the role of good information and self-efficacy in the career decision-making process, and much of the literature as well, provides specific guidance on how counsellors can influence high school career aspirations. He made emphasis on providing clear, correct information about career options and requirements, so that students can plan appropriately. Nwanko and Okwunzo (2010) conducted a study in Odoh State in Nigeria to find out how high school students are prepared for the job market and career choice. Their study adopted phenomenological qualitative design to further explore the lived experiences of counselled students. They reported that career decisions are mainly social, and approached their study from a social constructionist point of view. The study recommended development of guidance and counselling structures which could address specific students' career preparedness and decision making needs. In Uganda, Muzongondi (2012) conducted a study in three districts to determine how prepared secondary school students were concerning career decision-making. He used post-ex facto descriptive survey design. The study findings were that, only $8 \%$ of the sampled students had received counselling on career planning, preparedness and decision-making. Out of the 300 students, $82 \%$ had not received any special counselling in school while the remaining $10 \%$ had received other types of counselling other than career counselling but mostly outside the school setting. They concluded that counsellors had not made remarkable impact on students' career decision-making endeavours. Since career decision is perceived to have an impact on individuals' career ambitions and prosperity, they recommended formation of special counsellors to deal with career counselling only.

Other previous studies have been reported on gender differences and career awareness. A comprehensive report and data summary conducted by Ferris State University (2012) on a study which was done in 2002 in Michigan State about career guidance and decision-making among American youth: decisions without directions. The findings were that, both males and females are heavily oriented toward postsecondary education, but girls slightly but significantly exceeded the boys in their zeal for more schooling after high school. However, the study also found out that gender of the student 
appeared to have no significant effect on the likelihood of having made a career decision. The difference between a father-influenced student and a mother-influenced student amounted to this: father-influenced young people are 29 percent more likely to have made a career decision. Finally, most of the students made these decisions but did not know how to practically achieve or arrive at their dream careers because most of the counselling sessions did not exhaustively provide directions but only engaged them on requirements and benefits of certain careers. Newton and Grayson (2012), conducted a study in the State of Orlando to investigate why men and women shun some careers. Prior to comparing men's and women's career values, he demonstrated that the survey items used to measure these values function similarly across the two gender groups. Gender influences behaviours and preferences across a variety of contexts. While there is some debate about the degree to which these differences are biologically versus socially influenced, several notable trends have emerged. Among them are gender differences in interdependence and connectedness. One such study was done in Minnesota by Cross and Madson (2013), who found that when men and women were asked to select photos that described their lives, women selected more photos of others, while men selected more photos of themselves. This finding supports the notion that women have a tendency to define themselves based on social relationships and connectedness. Differences in male and female social behaviour may also be understood as differences in interdependence. They reported that, American men tend to view themselves as independent, while American women view themselves as interdependent. This self-construal as either independent or interdependent may form the basis for their cognitions, motivations, and emotions to career choices.

From the summarized literature above, some of the reviewed studies adopted different designs and data collection instruments. Two studies were conducted regionally however; none of these addressed the context of the current study. Finally, five studies were reviewed to address the second research question in the current study. Out of these, some were conducted in Western countries and adopted different contexts, respondents and methodologies. One study each was reviewed regionally and locally but adopted different methodologies other than descriptive survey. Therefore, the current study would fill in gaps in literature.

\section{Research Methodology}

\subsection{Research Design}

The study adopted descriptive survey design. This type of design is appropriate when independent variables are not manipulated and participants are not given a treatment that is measured as in typical experimental design (Kerlinger, 2010). This design was used in order to describe the role of guidance and counselling on public secondary school students' career decision-making in Marsabit Central district as it existed.

\subsection{Study participants}

The target population of students was 2,259 which is the total number of students' in public secondary school in the district. Furthermore, nine guidance and counselling teachers were also targeted for the study because they provided counselling services to the affected students. Out of nine public secondary schools in the district, 6 schools representing $67 \%$ were selected using simple random sampling method through SPSS version 22 . This sampling technique was used because it ensured that the "unknown" influences were equally distributed within the sample (Lincoln \& Guba, 2007). Therefore, 250 students representing $11.1 \%$ of the total 2,259 in the district were selected using stratified sampling technique. This is a technique that is used to acquire individuals with heterogeneous characteristics for the study (Bell, 2009). Six guidance and counselling teachers representing $67 \%$ of the 9 guidance and counselling teachers in the district were also randomly selected for the study.

\subsection{Research Instruments}

The researcher used questionnaires to elicit information from students and interview schedules to collect data from counseling teachers and principals. Questionnaires were used to acquire the necessary quantitative data from the students on the status of career awareness and career decision making among students in the selected schools. Content validity of the questionnaires was enhanced by the examination of the instruments by researcher's supervisors and participants of the pilot study. Therefore, the quantitative instrument (questionnaire) was amended after the supervisors' advice as preferred by Frankfort-Nachmias and Nachmias (2006). The content validation was therefore appropriate in 
determining the extent to which the set of items provided relevant and representative sample of the domain of tasks under consideration (Gronlund, 2005). In this study, the reliability coefficient of the items (on the Likert Scale) in the students' questionnaire was computed to yield figures above 0.6 and considered reliable (Cronbach, 2005).The trustworthiness of qualitative data was also ensured. For example, the researcher ensured credibility by the adoption of research methods that were well established, developing of an early familiarity with the culture of participating schools before the first data collection dialogues take place, iterative questioning, negative case analysis, frequent debriefing sessions, peer scrutiny of the research project, thick description of the phenomenon under scrutiny, and an examination of previous research findings to assess the degree to which the project's results were congruent with those of past studies.

\subsection{Data Collection Procedures}

The researcher sought permission from the Catholic University of Eastern Africa, the National Commission for Science, Technology and Innovation, Marsabit County and District Education Officer in Marsabit Central to conduct the study. When the permission was granted, the researcher made an official application through writing to the schools through their principals to be allowed to use the institutions for the study and categorically stated the purpose of the study and the target respondents. After being granted permission by the authorities of various institutions, the researcher visited the schools, read and issued informed consent forms to the selected participants. The participants were then signed the consent form and return it to the researcher agreeing to voluntarily participate in the study. The researcher further discussed a convenient day for administration of the research instruments to the participants whose consent had been obtained through informed consent forms. The researcher then distributed questionnaires to the selected students who consented to participate in the study by help of guidance and counselling teachers in the selected schools. The interviews were conducted by the researcher on guidance and counselling teachers and principals after the quantitative data from the questionnaires had been collected to avoid replication of information. The guidance and counselling teachers as well as principals were interviewed in their offices. Interview for each participant took between 35-45 minutes.

\subsection{Data analysis}

Data from the questionnaire was quantitatively analyzed in order to identify general trends in the selected population (Gall \& Borg, 2006). The analysis of quantitative data included descriptive, inferential and non-parametric statistics. Qualitative analysis was employed for data from the interview schedule because part of the research was based on an interpretive naturalistic approach as pointed out by (Christensen \& Johnson, 2010). The researcher used the thematic framework developed through deduction of meanings from the interview excerpts.

\section{Findings and Discussion}

\subsection{Findings on the status of career awareness among public secondary school students.}

The study sought to investigate the status of career awareness among secondary school students. To achieve this, career awareness questionnaire was developed using a five point Likert Scale with 20 items. Prior to this descriptive test, exploratory analysis had revealed that all the items were relevant to career awareness. As such, there were no significant outliers thus no item was removed from the students' career awareness questionnaire. Using a five-point scale ranging from 1 to 5, a cut-point of 3 was used for descriptive analyses. Any mean scores less than 3 denoted that majority of the respondents disagreed while mean scores above 3 indicated that the majority of the respondents agreed with the construct under scrutiny (status of career awareness). The descriptive statistics are presented in Table 1. 
Table 1: Descriptive Statistics on Status of Career Awareness

\begin{tabular}{lcc}
\hline Career Awareness & Mean & Std. Deviation \\
\hline I understand what career means & 4.56 & 1.014 \\
I am aware of various careers available in the country & 3.89 & .928 \\
I know the training requirements for various careers & 3.22 & 1.202 \\
I know various working conditions for careers & 3.11 & 1.453 \\
I know relationship between various jobs & 3.67 & 1.118 \\
I know my abilities in terms of career involvement & 4.11 & 1.364 \\
I know my career interest & 4.11 & 1.269 \\
I know careers that will give me optimum satisfaction & 3.89 & 1.054 \\
I have some experience in my career of choice & 3.67 & 1.000 \\
I know career environment in which I can work best & 3.56 & 1.236 \\
I know my career capabilities and limitations & 3.56 & 1.333 \\
I know careers that are available in the country & 3.00 & 1.118 \\
I know careers that pay well & 3.11 & 1.537 \\
I know dangers associated with some careers & 2.67 & .866 \\
I know employment rates for some careers in the country & 3.44 & 1.333 \\
I know myths associated with some careers & 2.78 & 1.563 \\
I know career status in the country & 2.89 & 1.167 \\
I know successful people in various careers & 3.11 & 1.537 \\
I know why I want to get into some careers & 4.11 & .782 \\
\hline
\end{tabular}

The results presented in Table 1 shows that mean scores obtained by students on career awareness ranged from 2.67 to 4.56. The highest ranked statements were; "I understand what career means" with a mean of 4.56. This was followed by "I know my abilities in terms of career involvement", "I know my career interest" and "I know why I want to get into some careers" all with means scores of 4.11 each. The rest of the items were "I am aware of various careers available in the country" (3.89), "I know careers that will give me optimum satisfaction" (3.89), "I know relationship between various jobs (3.67), "I have some experience in my career of choice" (3.67), "I know my career capabilities and limitations" (3.56), "I know career environment in which I can work best" (3.56), I know employment rates for some careers in the country" (3.44), "I know the training requirements for various careers" (3.22), "I know various working conditions for careers" (3.11), "I know careers that pay well" (3.11), "I know successful people in various careers" (3.11), "I know careers that are available in the country" (3.00). All these means were above the cut-point of 3 implying that the majority of the students agreed that they were aware of careers. This was attributed to the role played by guidance and counseling services in the sampled schools. The findings are similar to that of a Comprehensive Report and Data Summary conducted by Ferris State University (2012) and another study by Wanga and Ombima (2012) which revealed that that effective career counseling enable students to acquire the skills to investigate the world of work in relation to knowledge of self and to make informed career decision, employ strategies to achieve future career success and satisfaction and understand the relationship between personal qualities, education and training and the world of work.

However, some means were lower than the set median of 3: "I know career status in the country" (2.89), "I know myths associated with some careers" (2.78), and "I know dangers associated with some careers" (2.67). This indicated that majority of the students disagreed with the three items. The underlying implication concerning the three items with means below 3 is that students may not have been enlightened in those particular areas during counselling services. This could be due to the narrow scope adopted by counsellors or lack of information on those particular areas. These findings are similar to that of American School Counsellor Association (2010) which conducted a national study in California and found out that that school counsellors need to be informed consumers of research, and also need the necessary skills to conduct evaluation studies of their programs and interventions to help students make right career decisions.

\subsubsection{Chi-square test results on Status of Career Awareness}

The normality of the items on status of career awareness was tested though Kolmogorov-Smirnov Test before running Chi-square test. It revealed that the distribution of career awareness was normal with mean of 71.11 , standard deviation 11.75 and significance test of .893>p=.05. The Likert scale had five points strongly agree (5), agree (4), undecided (3), disagree (2) and strongly disagree (1). A cut-point of 3 was set and responses with means scores above 3 indicated 
majority of the respondents agreed while a mean below 3 depicted that the majority of the respondents disagreed. As such, chi-square was calculated using frequencies and percentages calculated from the frequency tables of the items on career awareness questionnaire. This is presented in Table 2.

Table 2: Chi-square test for status of career awareness among secondary school students

\begin{tabular}{|c|c|c|c|c|c|c|c|}
\hline Career awareness & SA & A & $\mathbf{U}$ & D & SD & Total & Chi square test \\
\hline I understand what career means & $70(36.8)$ & 10(5.3) & 0 & 10(5.3) & 0 & $90(47.4)$ & $X^{2}=56.250$ \\
\hline I am aware of various careers available in the country & $20(10.5)$ & $50(26.3)$ & $10(5.3)$ & 10(5.3) & 0 & $90(47.4)$ & \\
\hline I know the training requirements for various careers & $20(10.5)$ & 10(5.3) & $30(15)$. & $30(15.8)$ & 0 & $90(47.4)$ & \\
\hline I know various working conditions for careers & $10(5.3)$ & $20(10.5)$ & $10(5.3)$ & $30(15.8)$ & 0 & $90(47.4)$ & $d f=49$ \\
\hline I know relationship between various jobs & $20(10.5)$ & $40(21.1)$ & $10(5.3)$ & $20(10.5)$ & 0 & $90(47.4)$ & \\
\hline I know my abilities in terms of career involvement & $60(31.6)$ & 0 & $10(5.3)$ & $20(10.5)$ & 0 & $90(47.4)$ & \\
\hline I know my career interest & $40(21.1)$ & $40(21.1)$ & 0 & 0 & $10(5.3)$ & $90(47.4)$ & \\
\hline I know careers that will give me optimum satisfaction & $40(21.1)$ & 0 & $50(26)$. & 0 & 0 & $90(47.4)$ & \\
\hline I have some experience in my career of choice & $20(10.5)$ & $30(15.8)$ & $30(15)$. & 10(5.3) & 0 & $90(47.4)$ & \\
\hline I know career environment in which I can work best & $30(15.8)$ & $10(5.3)$ & $30(15)$. & $20(10.5)$ & 0 & $90(47.4)$ & \\
\hline I know my career capabilities and limitations & $10(5.3)$ & 10(5.3) & $40(21)$. & 0 & $30(15.8)$ & $90(47.4)$ & \\
\hline I know careers that are available in the country & $10(5.3)$ & 10(5.3) & $50(26)$. & 10(5.3) & 10(5.3) & $90(47.4)$ & \\
\hline I know careers that pay well & $20(10.5)$ & $20(10.5)$ & 20(10.) & 10(5.3) & $20(10.5)$ & $90(47.4)$ & \\
\hline I know dangers associated with some careers & $10(5.3)$ & $10(5.3)$ & $50(26)$. & $20(10.5)$ & 0 & $90(47.4)$ & \\
\hline I know employment rates for some careers in the country & $20(10.5)$ & $30(15.8)$ & 20(10.) & 10(5.3) & 10(5.3) & $90(47.4)$ & \\
\hline I know myths associated with some careers & $10(5.3)$ & $30(15.8)$ & $10(5.3)$ & 10(5.3) & $30(15.8)$ & $90(47.4)$ & \\
\hline I know career status in the country & 10(5.3) & 10(5.3) & $40(21)$. & $20(10.5)$ & $10(5.3)$ & $90(47.4)$ & Sig. $=0.001^{*}$ \\
\hline I know successful people in various careers & $20(10.5)$ & $20(10.5)$ & 20(10.) & $10(5.3)$ & $20(10.5)$ & $90(47.4)$ & \\
\hline I know why I want to get into some careers & $30(15.8)$ & $40(21.1)$ & 20(10.) & 0 & 0 & $90(47.4)$ & \\
\hline
\end{tabular}

The results presented in Table 2 indicated that students' career awareness had significant relationship with students', $\left(X^{2}=56.250, d f=49, p=0.001<0.05\right)$. This depicted that students who were aware of careers were able to make career decisions, while those who were not aware of careers had difficulty making career decisions. This implies that effective career guidance and counselling could help students to be aware of careers and this enabled them to be able to make right career decisions.

Qualitative findings obtained from the interview data also revealed different responses about coordination between counsellors, teachers and parents on career issues. One of the female students stated that:

Yes, they sit with head teacher and discuss how they can provide counselling services because usually, the class teacher or head teacher refer students to the counsellor [Female student 2].

This implies that guidance and counselling programs feature a team approach and needs co-operation from various stakeholders to make it effective. A female student added that often, parents, siblings and teachers tended to influence their knowledge of careers so that they can eventually end up in those professions that appeal to parents:

Adolescents are vulnerable to criticism, suggestions, and emotional appeals from others. Parents, friends, siblings, and teachers are all eager to add their own expectations and observations to even the brightest students' intentions and decisions. Often, others' expectations for talented young people compete with their own dreams and plans. In fact, our own expectations must stand against the strong current posed by the pressure of others' desires and demands. The dilemma is complicated by the numerous options within the reach of a highly talented student, the greater the talent, the greater the expectations and outside interference. Gifted adolescents consistently report dramatic episodes of being pushed to the point of doubt and despair by insensitive teachers, peers, and even parents. Teachers in secondary schools, in particular, have tried to disprove the talents of individual students, saying, in effect, "prove to me you are as gifted as you think you are". But coping with the vagaries of adolescence while also proving oneself again and again in the classroom or peer group significantly drains energy allocated for the normal tasks of adjustment and leads to frequent frustration and isolation [Female student 18].

These findings are similar to those by Clinedinst and Hawkins (2009) who reported that the level of career awareness among high school students enabled them to make right career decisions before they exit high school. The implication of these findings is that teacher counsellors, parents and teachers work together to ensure that students are well advised to avoid poor career decision making but often veer off the conventional methodology of helping 
adolescents choose own careers by intuitively coercing them to what they may not like.

However, there were contrary views posted by some of the students. One female student reiterated that: "parents are only involved in counselling issues when the student makes a mistake and is sent home. The issues of careers are rarely discussed between them" [Female student 4]. This implies that despite the coordination between parents, teachers and counsellors, it is still not well developed in all schools. Further, it may also be a result of weak guidance and counselling programmes in some schools. It is therefore imperative for all counselling units in all schools to ensure effective consultation model between the government, counsellors, teachers, parents and students.

During the interview carried out by the researcher, another school principal highlighted was career awareness among students. He stated that guidance and counselling units were not well developed in some schools hence, most students were not aware of the benefits of counselling: "There are a few students who know what they want to become but majority do not know" [Principal 1].

Further inquiry into whether students make career choices after counselling revealed different perspective from the principal who stated that:

No, they may not make right choices in some cases but some still do make the right career choices. The ability to offer proper career counselling depends on finances and human resources which most schools do not have. Therefore, it's hard to offer comprehensive services. [Principal 6].

The teacher counsellor also added that "we don't have enough hand books on guidance and counselling to be able to offer effective services" [Teacher counsellor 1]. These implied that shortage or lack of financial and human resources affected the counselling services in most school. It was not therefore offered effectively.

This finding complement that of Chapman (2010) who showed that the role of good information and self-efficacy in the career decision-making process, and much of the literature as well, provides specific guidance on how counsellors can influence high school career aspirations.

\subsubsection{Findings on relationship between career awareness and career decision making.}

Regression analysis was conducted to establish the ability of career awareness to predict career decision-making. Linear regression was considered important because it goes beyond correlation by offering prediction capabilities. Here, the researcher sought to establish how well awareness among secondary school students career predicted career decisionmaking among them. However, even when a regression coefficient was correctly interpreted as a rate of change of a conditional mean rather than a rate of change of the response variable, it was important to take into account the uncertainty in the estimation of the regression coefficient. Therefore, if the t-test for a regression coefficient was not statistically significant, it was not appropriate to interpret the coefficient. A better alternative was to say, "No statistically significant linear dependence of the mean of conditional variable on response variable was detected." The prediction was considered significant at $P>05$. The results are presented in Table 3.

Table 3: Regression analysis results on relationship between career awareness and career decision-making

\begin{tabular}{|c|c|c|c|c|c|c|c|}
\hline Model & Sum of Squares & df & Mean Square & $t$ & Sig. & \multicolumn{2}{|c|}{ 95.0\% Confidence Interval } \\
\hline Regression & 3.479 & 1 & 3.479 & .085 & .779 & Lower bound & Upper bound \\
\hline Residual & 286.521 & 7 & 40.932 & & & & \\
\hline Total & 290.000 & 8 & & & & .001 & 38.255 \\
\hline
\end{tabular}

Dependent variable: career decision-making

Predictor: (constant), career awareness

The findings in table 3 revealed that, $t$-statistics was $t=.085>p=.05$. This implied that the relationship between the dependent variable (career decision making) and the predictor (career awareness was not just due to the distribution through random sampling (chance). This is because only $8.5 \%$ of the relationship was due to chance. Specifically, career awareness by students predicted their ability for career decision-making. Therefore, there was a positive and significant relationship between career awareness and career decision-making. The findings were similar to those by Trusty (2006) who reported that career awareness and exploration among students gave them the knowledge to choose right careers according their interest and ability. However, because the size of the P-value for a coefficient says nothing about the size of the effect that variable is having on the dependent variable - it was possible to have a highly significant result (very small P-value) for a miniscule effect. As such it was imperative to interpret the prediction via confidence interval. The 95\% confidence interval for regression coefficients gave the same information. It was $95 \%$ confident that the real, 
underlying value of the coefficients that the researcher estimated fell somewhere in the $95 \%$ confidence interval. The confidence interval was not close to the mean square (3.479) than the t-statistics (.085) intuitively implying that career awareness positively predicted career decision making on secondary school students. This is similar to the findings by Muzongondi (2012) who found o that career decision-making derived its significance from career awareness.

The researcher also obtained qualitative data from the counselors how effective counseling demonstrates the ability of students to apply decision-making skills to goal setting and attainment. She posited that:

\begin{abstract}
This involves the ability of learners to use the process of decision making to identify and implement academic and career goals that sustain positive attitudes and behaviours during their schooling and throughout their lifetime. It emphasizes steps in the decision making process; consequences of decisions and choices; importance of goal setting and follow through; developing short- and long-term goals; generating alternatives and options; and responsibility for consequences of choices made [Teacher counsellor 3].
\end{abstract}

Career decisions should be informed by appropriate academic ability because careers are chosen based on academic performance. As such, the counselors were asked to elucidate the fact that students could demonstrate understanding of the academic preparation needed to choose from a wide range of postsecondary choices. The findings are contrary to those revealed in a study by Muzongondi (2012) conducted a study in three districts to determine how prepared secondary school students were concerning career decision-making. It was also imperative for the counselors to demonstrate knowledge of the factors involved in making career decisions. This is important because they are required to undertake extensive research on factors that influence students' career decision-making and counsel them appropriately. One of the teachers reiterated that this was not fully explored due to lack of resources but agreed that it is a program standard that needed consideration:

This standard involves the ability of the learner to apply knowledge and skills to career selection. It involves researching careers and the world of work; resources for researching; the use of technology; self knowledge; academic preparation needed for careers; and matching personal qualities, interests and abilities to career pathways [Teacher counsellor 1].

This is similar to Clinedinst and Hawkins' (2009) who reported that, the ability of students to apply knowledge and skills on career selection was dependent upon awareness created through effective guidance and counselling. The implication of this finding is that, students rarely make appropriate career choices where career guidance and counselling is not effective.

\title{
4.2 Findings based on gender differences in career awareness among public secondary school students.
}

The study also investigated the role played by gender differences in career awareness. As such, the fourth question sought answers on whether there were gender differences in career awareness among public secondary school students. For descriptive analysis, male was represented by 1 while female was represented by 2 . The cut-point to this scale was 1.5 thus, any mean less than 1.5 represented majority as male gender while mean above 1.5 represented female gender as the majority. The descriptive statistics results are presented in Table 4.

Table 4: Descriptive Statistics: Mean and standard deviation of students' gender

\begin{tabular}{lcccc}
\hline & N & Mean & Std. Deviation & Std. Error Mean \\
\hline Gender & 90 & 1.33 & .500 & .167 \\
Male & 60 & 1.03 & .321 & .029 \\
Female & 30 & .30 & .157 & .012 \\
\hline
\end{tabular}

The descriptive analysis of whole population (all gender) revealed a mean of 1.33 representing $66.7 \%$ with a standard deviation of .500 . This indicated that the majority of the respondents were male. There were six male and four female students. This gender disparity is consistent with previous findings and could be attributed to high dropout rate among girls than boys. The findings are contrary to those of a study carried out in Minnesota by Cross and Madson (2013) who found out that there were same male and female enrolment in schools. This finding implies that girl-child is not given much priority in terms of education in Marsabit. This is because of cultural and traditional practices including early marriages in the communities in this region. 


\subsubsection{Inferential Statistics: One Sample t-test on gender differences and career awareness.}

Because of the descriptive statistics did not give any relationships between gander and career awareness, it was important to establish this. As such, one sample t-test was used with a known percentage of $67 \%$ as the test value.

Table 5: One sample t-test results on gender difference on career awareness

\begin{tabular}{ccccccc}
\hline & & & \multicolumn{3}{c}{ Test Value $=.67$} \\
\cline { 2 - 5 } & & & & & \multicolumn{2}{c}{$95 \%$ Confidence Interval of the Difference } \\
\cline { 4 - 5 } Gender & .020 & 8 & Sig. (2-tailed) & Mean Difference & Lower & Upper \\
\cline { 4 - 6 }
\end{tabular}

The results in table 5 showed that, the $p$-value of the test was .985 which is greater than the level of significance 0.05 . It indicated that the percentage of students' perception was not significantly different from $67 \%$. The positive $t$ score implied that the sample proportion was greater than $67 \%$ but the evidence (based on the p-value) was insufficient to conclude that the perception of students in the population was significantly different from $67 \%$. Therefore, there were no relationship between gender difference and career awareness among the sampled students. This finding is contrary to that of Bland, Meurer and Maldonado (2012) who theorized in their study that there may be a function of gender differences in the values that influence students' career choices and one such value involves the desire to give comprehensive care for one's patients.

The data on gender and career awareness made inferential statistics (one sample t-test) less desirable. Therefore, a non-parametric test was also used for the two variables.

Table 6: Chi-square test results for gender difference in career awareness

\begin{tabular}{|c|c|c|c|c|c|c|c|}
\hline Gender & SA & A & U & $D$ & SD & Total & $\begin{array}{c}\text { Chi-square test } \\
x^{2}=9.00\end{array}$ \\
\hline Male & $20(33 \%)$ & $40(67 \%)$ & $0(0 \%)$ & $0(0 \%)$ & $0(0 \%)$ & $60(100 \%)$ & $d f=7$ \\
\hline Female & $20(67 \%)$ & $10(33 \%)$ & $0(0 \%)$ & $0(0 \%)$ & $0(0 \%)$ & $30(100 \%)$ & Sig. $=.253$ \\
\hline
\end{tabular}

*Significant at $p<.05$ level

The results in table 6 indicate a significance of .253. This is greater than .05 level, inferring that career awareness among secondary school students is not influenced by gender differences. Statistically, there is no significant relationship between gender and career awareness among secondary school students. Therefore, the secondary school students had equal chances of achieving career awareness despite their gender differences. This meant that effective career counselling will affect influence their career awareness equally and provide them with equal opportunity to make informed career decisions. These findings are similar to those by Newton and Grayson (2012) who found out in their study of gender and career that awareness among students was not a result of gender.

The interview of the teacher counsellor in one of the schools revealed similar to the quantitative information. The study sought to establish how gender influenced career decision-making among students.

Girls had a lot of work to do at home. They lacked enough time to concentrate well into making their vocation choices unlike boys. This affected many girls who sometimes got unexpected pregnancies that finally terminate their desired careers." However, boys have enough time on their side to study and make the right career decisions but due to harsh environmental conditions in Marsabit, some flee away from war torn areas and drop out of school. Both boys and girls have opportunity to make career decisions with the help of a mentor. [Teacher counsellor 2].

This implies that gender difference did not play a role in career decision-making among students in secondary school in Marsabit. However, the girls were disadvantaged because of high rate of dropout among them. Several challenges like early pregnancies and domestic work also played to their stay out of schools. The findings are similar to Newton and Grayson's (2012) who reported that girls were more susceptible to the societal vagaries in developing countries. This affected their schooling from an early and as a result, most did not attain good education.

\section{Concluding Remarks}

The study investigated the status of career awareness among public secondary school students in Marsabit Central 
district, Kenya. The results presented in Table 10 indicated that students' career awareness had significant relationship with students', $\left(X^{2}=56.250, d f=49, p=0.001<0.05\right)$. This depicted that students who were aware of careers were able to make career decisions, while those who were not aware of careers had difficulty making career decisions. This implies that effective career guidance and counselling could help students to be aware of careers and this enabled them to be able to make right career decisions. This implied that the relationship between the dependent variable (career decision making) and the predictor (career awareness was not just due to the distribution through random sampling (chance). This is because only $8.5 \%$ of the relationship was due to chance. Specifically, career awareness by students predicted their ability for career decision-making. Therefore, there was a positive and significant relationship between career awareness and career decision-making. Other findings were that, career awareness among secondary school students is not influenced by gender differences. Statistically, there is no significant relationship between gender and career awareness among secondary school students. Therefore, the secondary school students had equal chances of achieving career awareness despite their gender differences. It was proposed that, in future, other studies could be conducted to investigate the competencies needed for counsellors in dealing with the problem of poor career decision making.

The study recommended that, school counsellors should provide a systematic approach to helping all students with the decision making process, to understand; themselves and to develop appropriate goals through the interpretation of standardized test results and course performance. Moreover, the teacher counsellors should identify personal beliefs and philosophies as to how all students benefit from the school counselling program and act on these beliefs and philosophies to guide the development, implementation and evaluation of a comprehensive school counselling program.

\section{References}

Chapman, D. W. (2010). "Students' Perceptions of the Effectiveness of Public School Counselors in College Advising." The School Counselor, 38, 268-278.

Cheek, J.R., Bradley, L.J.,Reynolds, J. \& Coy,D. (2012). "An intervention for helping elementary students reduce test anxiety" Professional School Counseling, 2, 162-164.

Christensen, L. \& Johnson, B. (2010). Educational Research. (3rd Ed). New Delhi: Sage Publications Inc.

Clinedinst, M. E. \& Hawkins, D. A. (2009). State of College Admission. California: National Association for College Admission Counseling.

Cronbach, L. J. (2005). "Test 'reliability': Its meaning and determination." Psychometrika, 12, 1-16.

Cross, S. E., \& Madson, L. (2013). "Models of the self: Self-construals and gender." Psychological Bulletin, 122, 5-37.

Duda, F. (2006). Guidance and counseling. A case study of Machakos Municipality. Unpublished PGDE Thesis, Nairobi: Kenyatta University.

Frankfort-Nachmias, C. \& Nachmias, D. (2006). Research Methods in Social Sciences (5 th Ed) New York: Replika Press Pvt. Ltd.

Gall, M.D, Borg, W.R. \& Gall, J.P. (2006). Educational Research. An introduction. New York: Longman Publishers.

Gazda, C.M. (2008). Group Counseling: A Developmental Approach. (3rd ed). Massachusetts: Allyn and Bacon, Inc.

George, R.L. \& Cristiani, T.S. (2012). Counseling Theory and Practice. (3rd ed.). New Jersey: Prentice Hall.

Gronlund, N. E. (2005). Assessment of Students Achievement. Michigan: Allyn and Bacon.

Kerlinger, F.N. (2010). Foundations of Behavioural Research (5th Ed.). New Delhi: Holt, Rinehart and Winston Inc.

Lincoln, Y. S., \& Guba, E. G. (2007). "Criteria for assessing the trustworthiness of naturalistic Inquiries." Educational Communication and Technology Journal, 29, 75-91.

Makinde, O. (2006). Fundamentals of Guidance and Counseling. London: Macmillan Educatio Limited.

McLeod, J. (2007). Research and Evaluation in Counselling. New York: Routledge.

Muzongondi, J. (2012). "The effects of a comprehensive guidance model on a rural school's counseling program." Ugandan Elementary School Guidance and Counseling, 25(1), 37-45.

Newton, D. A., \& Grayson, M. S. (2012). "Trends in career choice by US medical school graduates." Journal of the American Medical Association, 29, 36-40.

Nwanko, M., \& Okwunzo, S. (2010). "The effects of participation in group counseling sessions on self-esteem and locus of control among adolescents from divorced families." The Ife School Counselor Journal, 36, 54-60.

Rob, F. \& Achola, K. (2008). Real World Research for social scientists (2nd Ed). Oxford: Blackwell Publishing.

Savickas, M. L. (2012). The theory and practice of career construction. Hoboken, NJ: Wiley.

Strong, T. (2009). "Getting Curious About Meaning - Making in Counseling." British Journal of Guidance and Counseling, 31, $259-273$.

Super, D. W. (2007). "A life-span, life-space approach to career development." Journal of Vocational Behavior, 16, $282-298$.

Trusty, J. (2006). "Effects of high school course-taking and other variables on choice of science and mathematics college majors." Journal of Counseling \& Development, 80(4), 464-475.

Wango, G. (2006). Policy and Practice in Guidance and Counseling in Secondary schools in Kenya. Unpublished PhD Thesis, United Kingdom. University of Birmingham.

Watts, A.G. (2010), "National All-Age Career Guidance Services: Evidence and Issues", British Journal of Guidance and Counseling, 8, $31-44$. 
ISSN 2239-978X

ISSN 2240-0524
Journal of Educational and Social Research MCSER Publishing, Rome-Italy
Vol. 4 No. 6 September 2014 